\title{
An English Translation Teaching Model Based on Interactive Reading Theory
}

\author{
https://doi.org/10.3991/ijet.v13i08.9047 \\ Yongfeng Yang \\ Taizhou Polytechnic Institute, Taizhou, China \\ 2248811599 @q . com
}

\begin{abstract}
With the development of economy, translators are facing increasingly higher demands and requirements in the society. However, the status quo of translational English teaching in college as an important way to cultivate English translators is still unsatisfactory. The monotonous and obsolete English teaching model severely limits the development of students' thinking, leads to insufficient innovation in the comprehension of English translation and makes it difficult for students to master English translation skills. In this study, interactive reading theory was used as the teaching method and Chinese learners' English corpus and self-built corpus were used as the teaching basis to design the corresponding teaching process according to the process and stages of meme reproduction. The results show that compared with traditional teaching, the English translation teaching model based on interactive reading theory can help students master English translation skills according to the rules of Englishcentered memory, thereby stimulating their interest in English translation and improving their English translation level.
\end{abstract}

Keywords-Teaching model; Interactive reading theory; English translation

\section{$1 \quad$ Introduction}

English translation not only presents an alternative way to learn English but also refers to the process of seeking similarities between two completely different linguistic and written symbols. When translating one language to another, these two languages must be connected through their linguistic similarities. This process not only refers to the superficial transformation of written symbols but also focuses on finding a deeper cultural connotation behind these symbols. This essence of translation must be highlighted when cultivating qualified translators in order for them to not only convert words by meaning but also effectively understand the deep cultural connection between these words. Students must develop such way of thinking to accurately express the meaning of the content that they are translating [1].

However, the traditional English translation teaching model does not satisfy the corresponding English translation teaching needs mentioned above. This model identifies the evaluation criterion of the entire teaching effect as the result of the English translation process and mostly neglects the entire English translation process. In this 
case, the in-depth understanding of students about the background and cultural connotation of the words they are translating cannot be cultivated and promoted [2]. The traditional teaching mode for English translation also begins with teachers explaining English translation theories and methods. Students can intuitively learn English translation skills and gradually form their own translation models. However, these models do not give students with enough room to think during the translation process, thereby preventing them from producing literary and artistic English translation results [3]. To address this problem, a new English translation teaching model that can help students achieve "fidelity, fluency, and elegance" in the entire English translation process must be developed.

\section{State of the art}

Foreign language translation teaching in China is still in its infancy. Many foreign language teaching models have been proposed since the 1970s, among which the interactive teaching model is considered the most mainstream. This model can be divided into the face-to-face classroom interactive model and the non-face-to-face network interactive model, which represent the interactions between the students and teachers and among students, respectively [4]. Fahrutdinova [5] suggested that the interactive model of foreign language translation can effectively improve the thinking habits of students throughout their learning process and promote their use of foreign language translation skills. When applying a teaching model, Pozdeeva [6] argued that studies on foreign language translation teaching models must begin with the complex and multi-level aspects of foreign language translation teaching and the continuous integration of teaching models throughout the entire education process. Matukhin [7] divided the entire foreign language translation process into three stages, namely, the recognition, construction, and paraphrase stages, all of which are applied in foreign language teaching courses to realize better teaching outcomes.

English is the main target of studies on foreign language translation teaching models in China. Since the 1990s, the Chinese education community has conducted many explorations of foreign language translation teaching systems and models, with most scholars focusing on the interactive teaching model. Wu [8] explored five types of interactive classroom teaching models, including thematic discussion, problem induction, typical cases, situation creation, and multidimensional speculation. By studying these five types of interactive teaching, she highlighted the feasibility of applying the interactive teaching model in classroom teaching. Meng et al. [9] examined the feasibility of applying the interactive teaching method in the English translation teaching model and developed an interactive English translation classroom teaching model with the principles of "learning warm-up-reading training-explanation-role playgroup discussion-detection-assignment." In response to the deepening informative education process, Jin [10] combined the current state of online education development and proposed a model for teacher-student interaction under the network education environment. In this model, teachers can use online platforms and teaching forums to re-plan and define their entire teaching process, while students can exchange 
classroom knowledge with their teachers and classmates through email and online forums.

Local and foreign studies on foreign language and foreign language translation teaching have defined the ideal teaching model as an interactive English teaching model based on classroom interaction. A dynamic cooperation between teachers and students can be achieved during the entire teaching process, and the transfer and exchange of quality inspection information are conducive to the joint development of students and teachers in the entire teaching process. Therefore, the English translation classroom teaching model must focus on the interaction between teachers and students and on the initiative of students to promote exploration and innovation in their overall learning process.

\section{$3 \quad$ English Translation Teaching Model Based on Interactive Reading Theory}

Interactive reading theory serves as the theoretical basis of the English translation teaching model. According to this theory, the entire teaching system of the corresponding English translation teaching model is quite large. Although the current teaching contents and methods are continuously being updated, the English translation teaching mode based on interactive reading mainly aims to form a relatively functional English translation teaching model system that can meet the current teaching goals. The main design objective of this system is to provide a human interface for teachers and students of English translation. This interface aims to improve the interactions among students and between teachers and students. This system can be divided into the online teaching, online administration, teaching resource management, and courseware development subsystems, all of which are developed by using ASP technology and JavaScript language. The teaching information and course resources of this system are stored in the SQL Server 2000 database.

Three major roles, including administrators, students, and teachers, are assigned in this system, with each role having specific rights to use the system. After logging in, the teachers are presented with a targeted interactive interface based on the current learning conditions and characteristics of their students. However, the interactive interfaces presented to students are mainly divided into seven sections, including online classrooms, online Q\&A, non-online Q\&A, submitting assignments, viewing assignment results, online exercises and tests, and downloading electronic resources. The contents of the current course are listed in each section based on the current learning situation of the students. These students can click on the course title to enter a learning section that corresponds to the course content. The specific interactive interface presented to teachers in the entire system is similar to that presented to the students. However, each section of this interface shows different functions compared with that presented to the students. For example, when a teacher enters the interface of the online test subsystem, the system manages the question database and the course resources. However, when a student enters the online test subsystem, the system manages online exercises and tests. Such interactive interface effectively provides stu- 
dents with targeted learning resources and contact methods as well as prevents an abuse of resources. The English translation teaching model system based on interactive reading theory allows teachers to effectively teach their students based on their aptitude levels and then presents personalized content on the entire interactive interface. The basic flow chart of the interactive reading-based teaching model is shown in Figure 1.

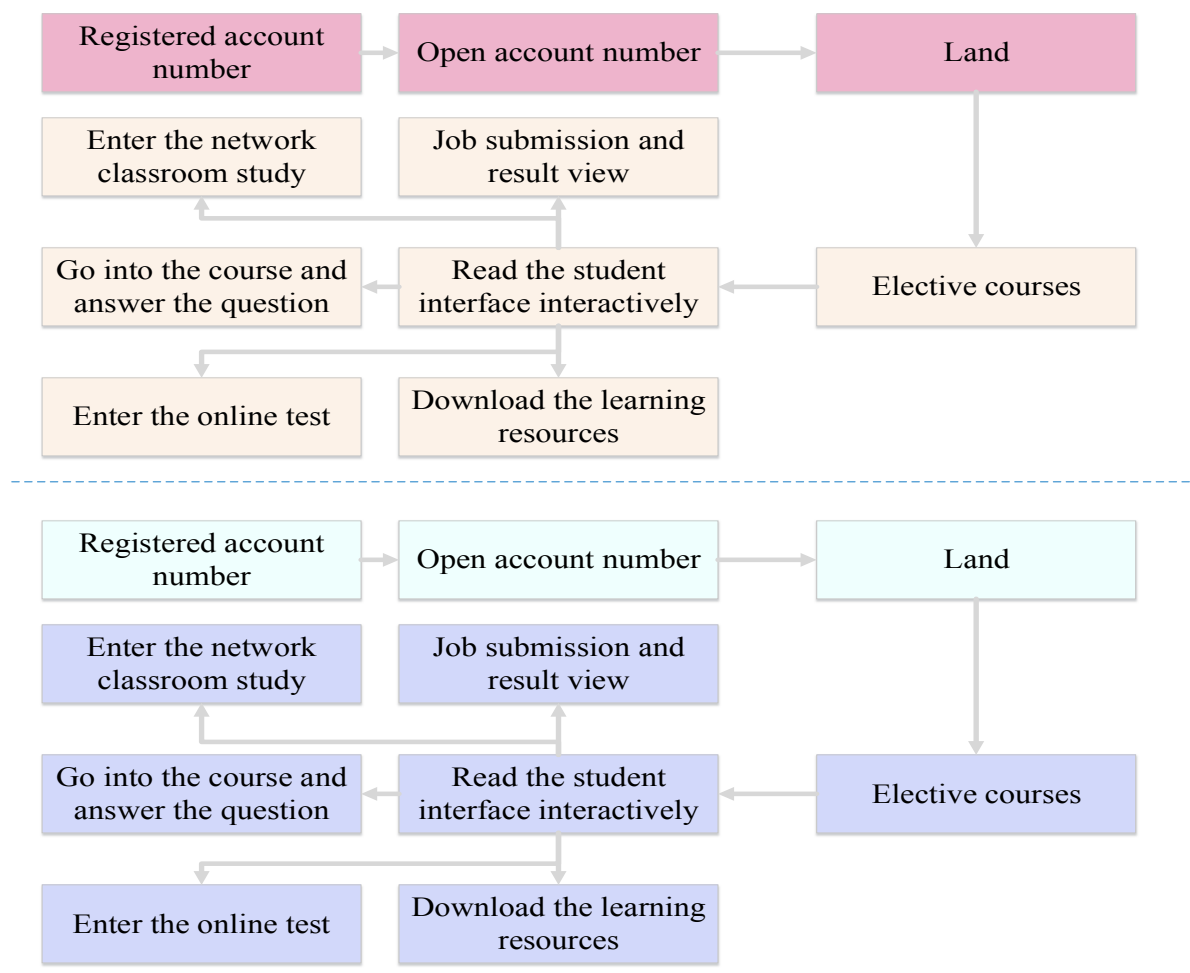

Fig. 1. Flow chart of the interactive reading-based teaching model

\subsection{Main framework of the English teaching model based on interactive reading theory}

The English translation course mentioned above was selected as the main application course of the teaching model proposed in this study. When considering the current status and requirements of English teaching, the proposed English teaching model mainly includes four subsystems, namely, the online teaching support, teaching resource management, online educational administration, and courseware development subsystems. The content and main functions of these subsystems are shown in Figure 2.

Among these subsystems, the online teaching support subsystem is the most important part of the proposed teaching model as it can effectively simulate any actual classroom teaching process and simultaneously perform real-time or non-real-time 
classroom teaching. Through the online teaching support subsystem, students can engage in an independent study of the entire course during their learning process; this subsystem also includes a module for the interactions among students and between teachers and students. The main function of this interactive module is to allow students and teachers to establish a real-time or non-real-time interactive contact in order to effectively deal with the challenges faced by the former in learning English translation. The online teaching support subsystem also includes online exercises and tests. The test module in this subsystem can formulate exercises and test questions based on the current learning situation of students as well as identify the current learning situation and learning outcomes of students through exams.

The main function of the online educational administration subsystem is to solve the teaching-related problems that are encountered during the operation of the proposed teaching model. This subsystem can also be divided into three modules, namely, educational administration management, course management, and system management. The educational administration management module mainly registers and manages the online academic status, learning, and files of students and the evaluation of teachers, while the course and system management modules manage the course of teachers as well as the course selection and attendance of students.

The teaching resource management subsystem mainly aims to store and manage the current English classroom teaching resources and teaching information, while the courseware development subsystem primarily aims to provide teachers with a highly integrated and easy-to-use courseware development module. By using templates, teachers can provide their students with a rich amount of classroom resources and environments by combining the available resources. The interactive operation steps of the RangeGSLAWL module are shown in Figure 3.

Interactive teaching tools support
The support of information technology

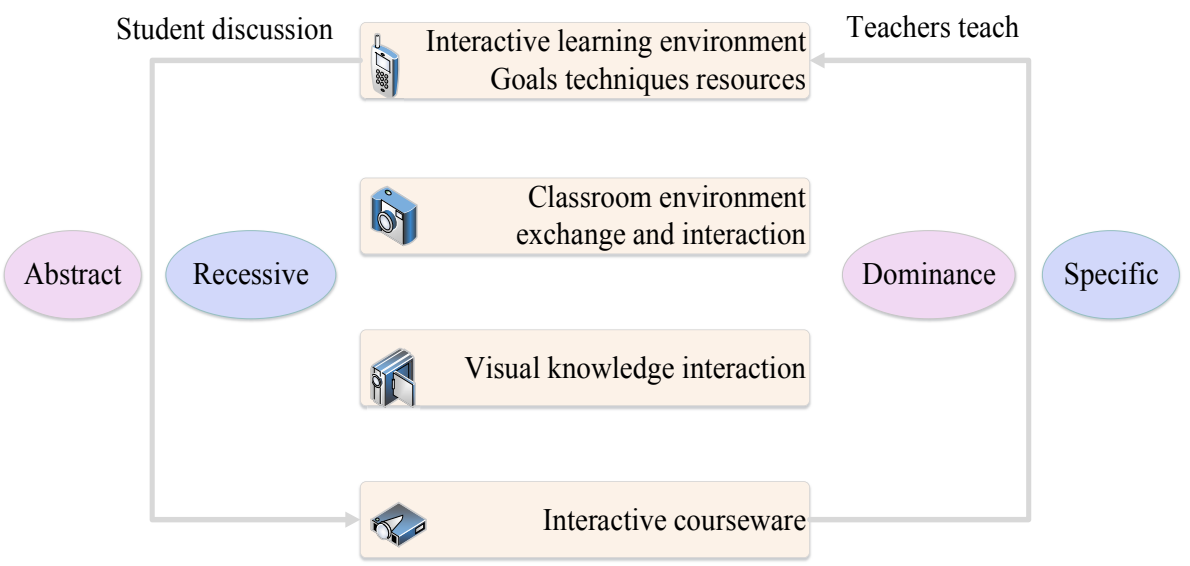

Fig. 2. Basic components of the teaching model based on interactive reading theory 


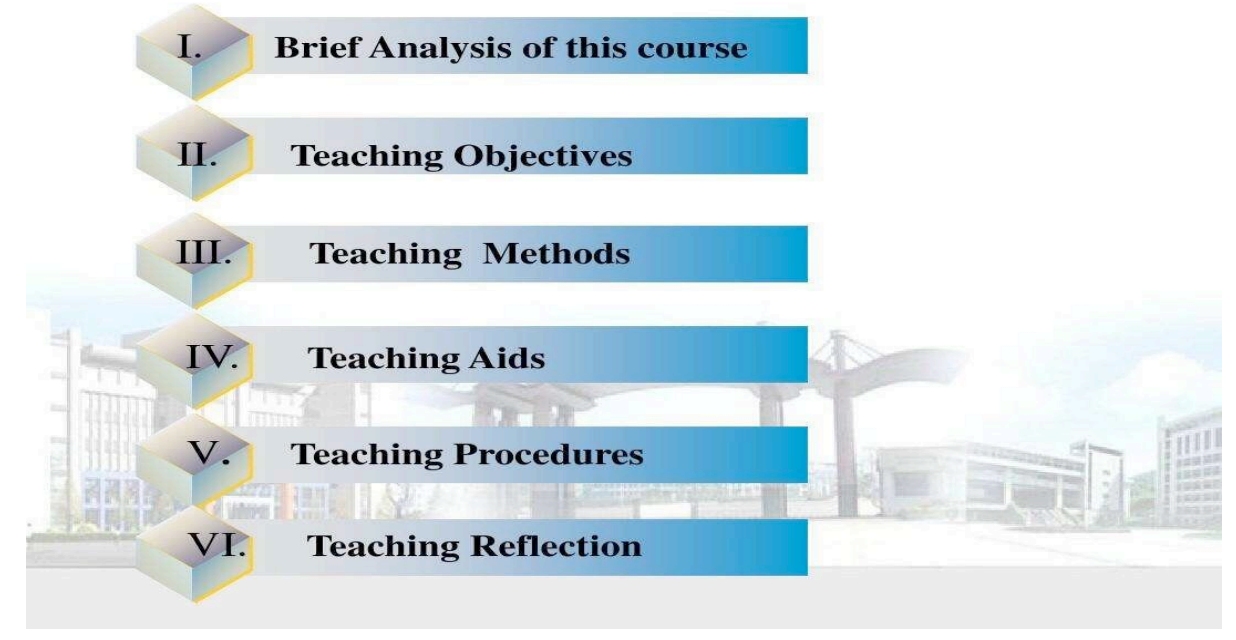

Fig. 3. Operation I of the English teaching model based on interactive reading theory

\subsection{Modules of the English teaching model based on interactive reading theory}

The lexical analysis tool RangeGSLAWL and the English translation corpus were primarily used in the modular construction of the proposed teaching model. The RangeGSLAWL module divides the vocabulary of English learning materials that are currently being used in China into three parts. The first part includes the 1556 English words that must be mastered in junior high school, the second part includes the 3170 English words that must be mastered in high school, and the third part includes the 3648 English words that must be mastered for the CET-4. The interactive operation interface of this module is shown in Figure 3, where 1 denotes the menu bar, 2 denotes the search column that receives the inputs of the user, and 3 and 4 denote the corpus search result columns. A labeling function is also provided in the RangeGSLAWL module. Figure 4 shows the labeling interface of the entire module, where 1 denotes the code list from which the files to be labeled and the files containing labels are selected, 2 denotes the list of labeling categories, and 3 denotes the shortcut menu that is displayed after right-clicking the item to be labelled. As an example, the three syntactic features of sentences with the modal verb "can" may be labeled as affirmative (aff)/negative (neg), declarative (dec)/interrogative (inte), and main clause (main)/subordinate clause (sub)/coordinated sentence (cor) (Deshorts, 2010: 114-115).

The text processing interface is also included in the RangeGSLAWL module as shown in Figure 5, where 1 denotes the file from where the corpus is selected, 2 denotes the inputted search item and file name, 3 denotes the file name filtered with a regular expression, and 4 denotes the text that meets the search conditions. 


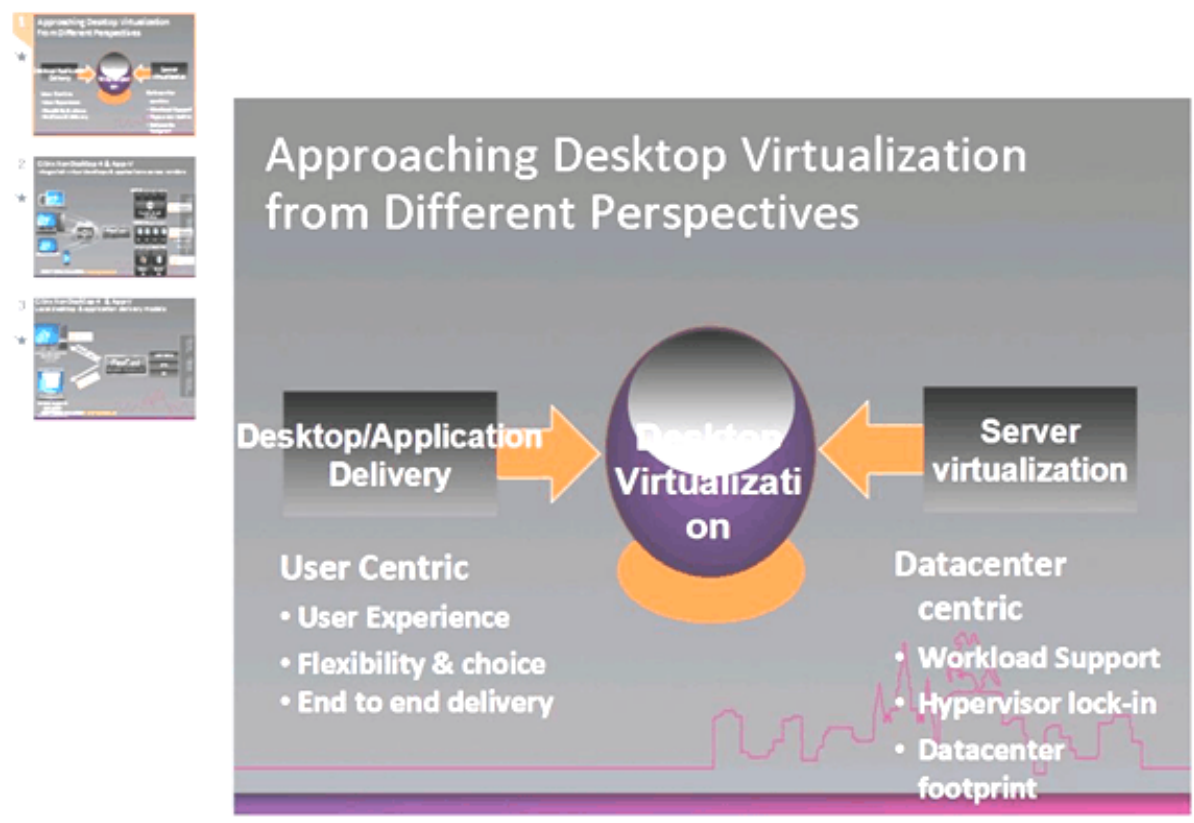

Fig. 4. Operation II of the English teaching model based on interactive reading theory

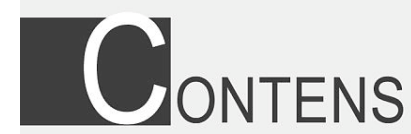

(D) Professional introduction

PART and lighting design

\section{(1) light poet}

()4

PART — Ingo Maurer

(D) Ingo Maurer design style

ART appreciation

PART Works introduction

(D) Conclusion

PART

Fig. 5. Operation III of the English teaching model based on interactive reading theory

The corpus used in the English translation course was made by non-English major college students and by the researcher for the Chinese Learners English Corpus. The structure of the entire corpus is shown in Figure 6. 


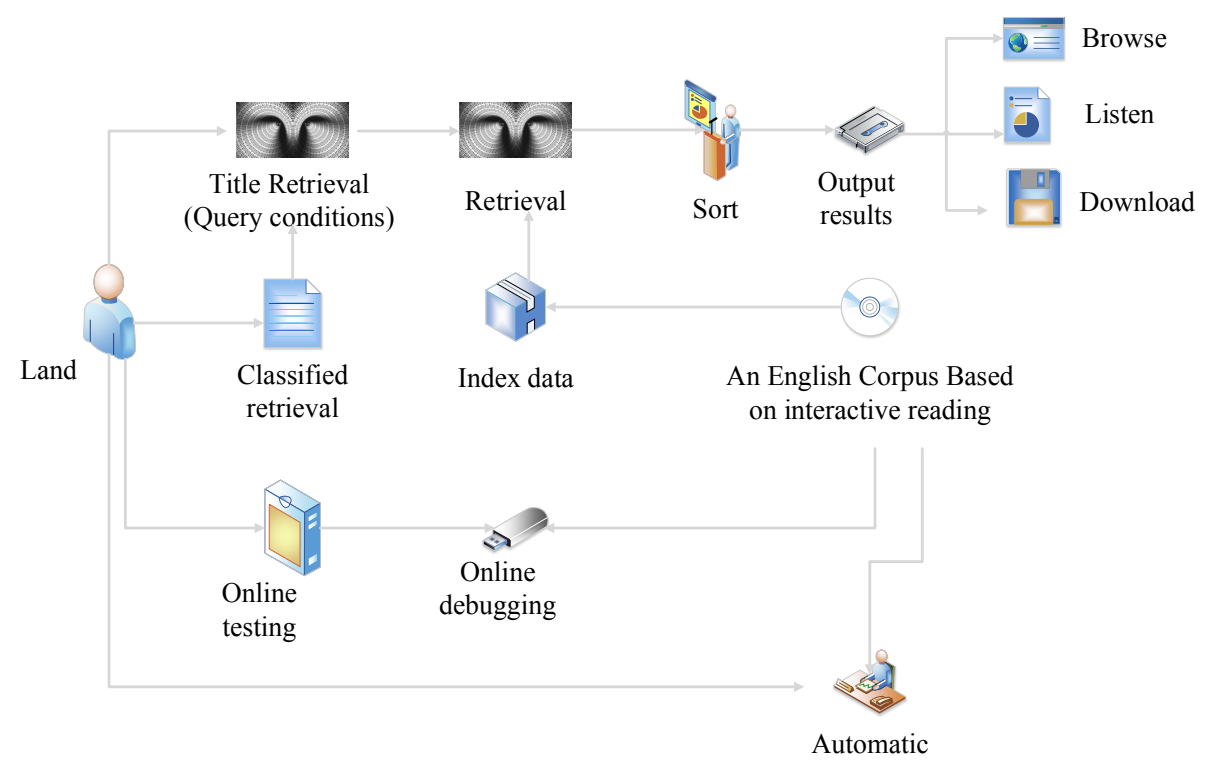

Fig. 6. Structure of the English corpus for interactive reading

\section{$4 \quad$ Teaching Example and Teaching Effect}

\subsection{Teaching example}

To test the teaching effect of the proposed teaching model, 69 first year undergraduate students of English translation were recruited as test objects. Throughout the entire test process, these students were categorized into three groups, with each group including 23 students. These three groups were labeled as experiment group 1, experiment group 2, and control group. The students in experiment group 1 initially engaged in an actual classroom instruction of the English translation course and then learned this course through the proposed English teaching model based on interactive reading theory. The students in experiment group 2 initially learned English translation through the proposed English teaching model based on interactive reading theory and then engaged in actual classroom instruction. The students in the control group adopted the traditional teaching model and engaged in self-review after completing the course. The teaching process in experiment groups 1 and 2 mainly followed the classroom learning pattern shown in Figure 7 and the classroom interactive principle shown in Figure 8. 
Paper-An English Translation Teaching Model Based on Interactive Reading Theory

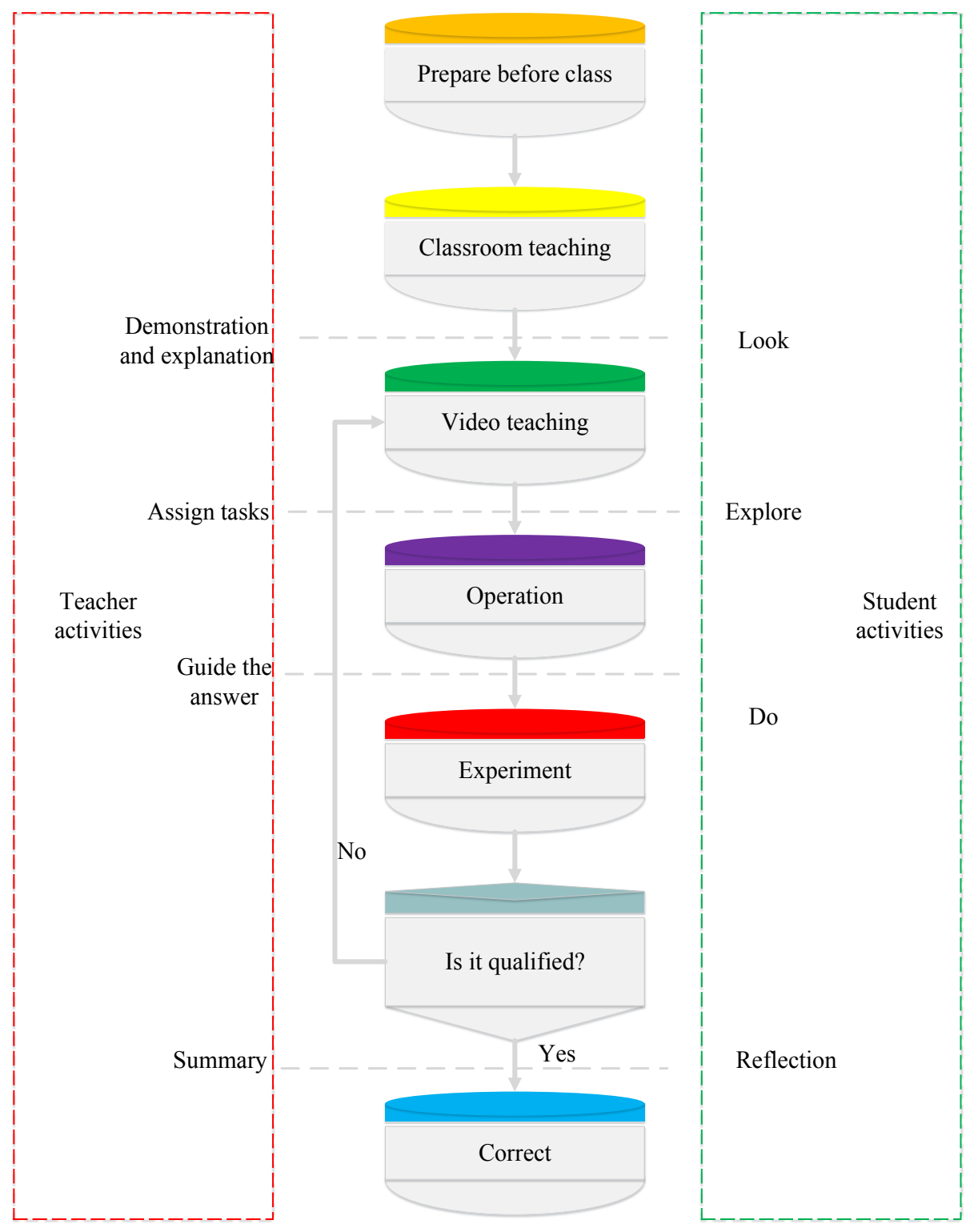

Fig. 7. Structure of the English teaching model based on interactive reading theory 


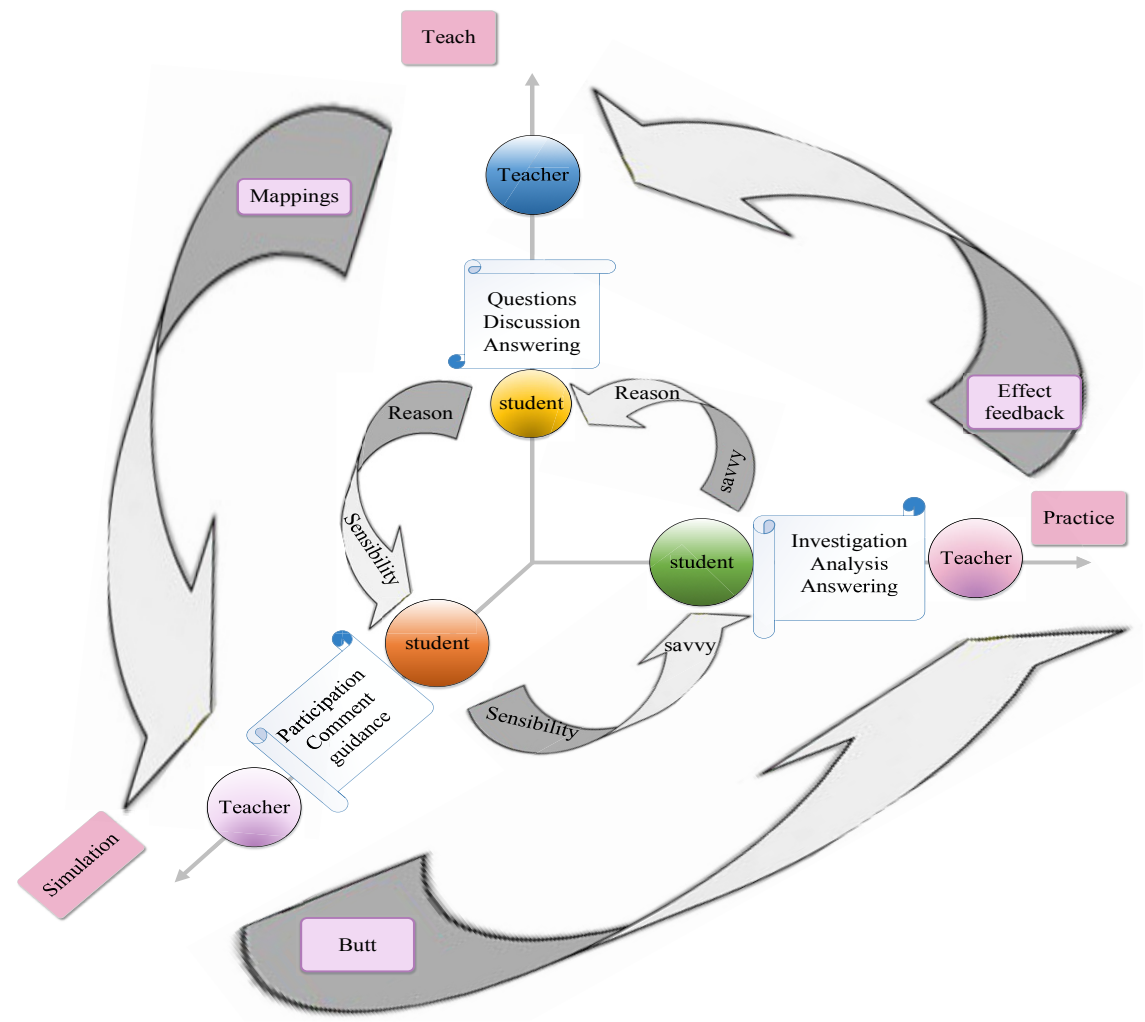

Fig. 8. Interactive principle of the English teaching model

\subsection{Teaching effect}

After the experiments, a survey was conducted to measure the agreement of the students and teachers on several statements for English translation recognition. The survey results are shown in Figure 9. The teachers and students participating in the questionnaire survey answered "strongly agree" or between "strongly agree" and "fully agree" for the statements "English translation is an interactive process," "English translation is inseparable from adequate language knowledge," "English translation cannot be separated from the role of accumulated knowledge and context," and "Visual information and non-visual information are equally important in the process of English translation."

Figure 10 compares the agreement of teachers and students on the statements for the advantages of the proposed English teaching model over the traditional English translation teaching model after participating in the English translation course. They answered "strongly agree" or between "strongly agree" and "fully agree" for the statement "Compared with the traditional English translation teaching model, the English teaching model based on interactive reading can 'improve the students' English translation skills,' 'help improve the students' interest in English translation,' and 
'enhance the students' self-confidence in English translation," while most respondents answered "slightly agree" for the statement, "Compared with the traditional English translation teaching model, the English teaching model based on interactive reading is more conducive to cultivating the students' consciousness of learning English translation and to enhancing the students' motivation of learning English translation."

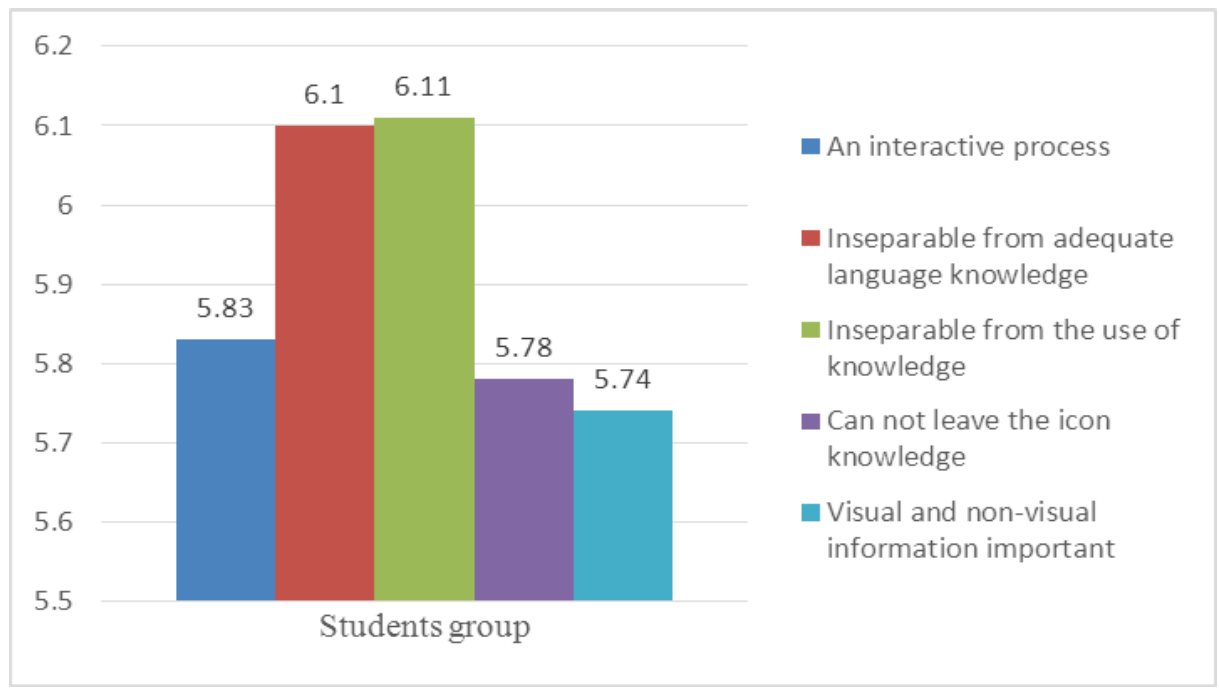

Fig. 9. Comparison of the degree of agreement of teachers and students on each statement for the English translation cognition process

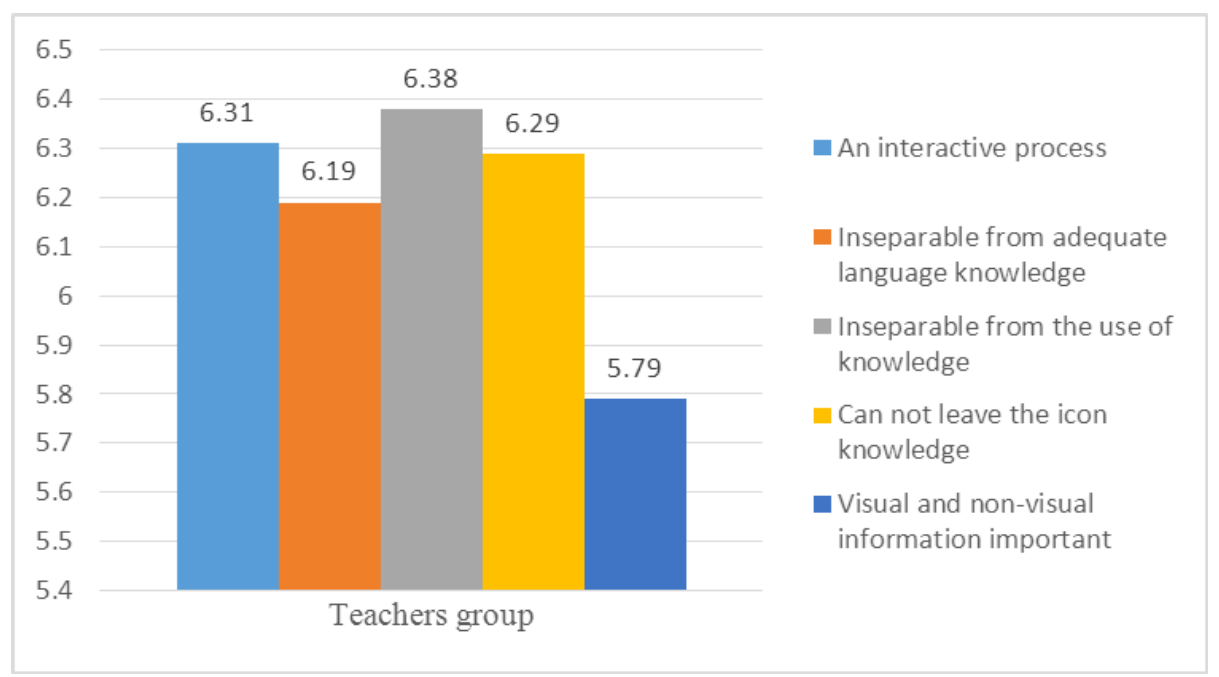

Fig. 10.Comparison of the degree of agreement of teachers and students on each statement for the English teaching model based on interactive reading theory 


\section{Conclusions}

The proposed English translation teaching model based on interactive reading theory can effectively improve the interest of students in English translation and increase their English translation level.

1. From the perspective of interactive reading theory, this English teaching model can effectively enhance the interaction among students, classroom knowledge, and teachers and can effectively improve the knowledge absorption and digestion of students.

2. The proposed English teaching model can integrate the learning motivation and learning enthusiasm of students into the entire English translation learning process. Therefore, this model plays an indispensable role in improving the overall quality of students.

3. In the proposed English teaching model, teachers can guide their students throughout their learning process and help them effectively improve their learning. They can also acquire teaching experience and improve their teaching abilities based on how students evaluate their teaching process. This teaching model can also establish a link between teachers and students, thereby allowing them to think and develop together.

\section{$6 \quad$ References}

[1] Arta, R. The Role of Screen Capture Technology in Translation: A Case Study of ProcessOriented Translation from English into Persian. Modern Journal of Language Teaching Methods, 2015, vol. 5(4), pp. 178-199.

[2] Yang, N. Effects of Interaction of Multimedia in Vocational College English Teaching. China Educational Technology \& Equipment, 2013, vol. 40(12), pp. 1380-1387.

[3] Topkaya, E.Z., Uztosun, M.S. Choosing Teaching as a Career: Motivations of Pre-service English Teachers in Turkey. Journal of Language Teaching \& Research, 2012, vol. 3(1), pp. 126-134. https://doi.org/10.4304/jltr.3.1.126-134

[4] Shen, P.P. Research on the New Modern English Teaching Mode in Higher Vocational Colleges based on Multimedia and Interactive System. International Technology Management, 2016, vol. 7, pp.54-56. https://doi.org/10.12783/dtssehs/isetem2016/4420

[5] Fahrutdinova, R.A., Fahrutdinov, R.R., Yusupov, R.N. The Model of Forming Communicative Competence of Students in the Process of Teaching the English Language. International Journal of Environmental \& Science Education, 2016, vol. 10(6), pp. 921-939

[6] Pozdeeva, S., Obskov, A. Justification of the Main Pedagogical Conditions of Interactive Teaching a Foreign Language in High School. Procedia - Social and Behavioral Sciences, 2015, vol. 206, pp. 166-172. https://doi.org/10.1016/j.sbspro.2015.10.047

[7] Matukhin, D., Bolgova, D. Learner-centered Approach in Teaching Foreign Language: Psychological and Pedagogical Conditions. Procedia - Social and Behavioral Sciences, 2015, vol. 206, pp. 148-155. https://doi.org/10.1016/j.sbspro.2015.10.044 
Paper-An English Translation Teaching Model Based on Interactive Reading Theory

\section{Author}

Yongfeng Yang is a lecturer in the Taizhou Polytechnic Institute, Taizhou 225300, China(2248811599@qq.com).

Article submitted 23 February 2018. Resubmitted 14 April 2018. Final acceptance 23 July 2018. Final version published as submitted by the author. 